\title{
Clostridium DifFicile RIBOTYPES 001,017 , AND 027 ARE ASSOCIATED WITH LETHAL C. DIFFICILE INFECTION IN Hesse, Germany
}

\author{
M Arvand (mardjan.arvand@hlpug.hessen.de) ${ }^{1}$, A M Hauri ${ }^{1}$, N H Zaiss², W Witte ${ }^{2}$, G Bettge-Weller ${ }^{1}$ \\ 1. Hesse State Health Office, Centre for Health Protection, Dillenburg, Germany \\ 2. Robert Koch Institute, Wernigerode, Germany
}

This article was published on 12 November 2009.

Citation style for this article: Arvand M, Hauri AM, Zaiss NH, Witte W, Bettge-Weller G. Clostridium difficile ribotypes 001, 017 , and 027 are associated with lethal C. difficile infection in Hesse, Germany. Euro Surveill. 2009;14(45):pij=19403. Available online: http://www.eurosurveillance.org/ViewArticle.aspx?ArticleId=19403

From January 2008 to April 2009, 72 cases of severe Clostridium difficile infection were reported from 18 different districts in the state of Hesse, Germany. A total of 41 C. difficile isolates from 41 patients were subjected to PCR ribotyping. PCR ribotype (RT) 027 was the most prevalent strain accounting for 24 of $41(59 \%)$ of typed isolates, followed by RT 001 (eight isolates, 20\%), RT 017 and 042 (two isolates each), and RT 003, 066, 078, 081, and RKI-034 (one isolate each). Eighteen patients had died within 30 days after admission. C. difficile was reported as underlying cause of or contributing to death in 14 patients, indicating a case fatality rate of $19 \%$. The patients with lethal outcome attributable to $C$. difficile were 59-89 years-old (median 78 years). Ribotyping results were available for seven isolates associated with lethal outcome, which were identified as RT 027 in three and as RT 001 and 017 in two cases each. Our data suggest that $C$. difficile RT 027 is prevalent in some hospitals in Hesse and that, in addition to the possibly more virulent RT 027, other toxigenic $C$. difficile strains like RT 001 and 017 are associated with lethal C. difficile infections in this region.

\section{Introduction}

Clostridium difficile infection (CDI) is a major cause of morbidity and mortality from healthcare-associated infections in economically developed countries. CDI is primarily linked with hospital admission and prior antimicrobial treatment. The symptoms can range from mild diarrhoea to serious manifestations such as pseudomembranous colitis, toxic megacolon or perforation of colon [1]. In recent years, a hypervirulent strain, which has been characterised by pulsed field gel-electrophoresis as North American pulsed-field gel electrophoresis type 1 (NAP1) and by PCR as ribotype (RT) 027, has emerged in North America, Canada, and several European countries [2-6]. This strain has primarily been described in association with hospital outbreaks but may also cause community-acquired infection. RT 027 is characterised by production of $C$. difficile toxins $A$ and $B$ and a third toxin (binary toxin), deletions in the regulatory gene tcdC that potentially allow increased toxin $A$ and $B$ production, and resistance to new fluoroquinolones such as moxifloxacin $[7,8]$.

In Germany, a hospital associated outbreak of the $C$. difficile RT 027 strain was reported in 2007 from Rheinland-Palatina in south-western Germany [9]. Since then, RT 027 has sporadically been isolated in other geographic regions of Germany [10]. A recent study found a high prevalence (55\%) of C. difficile RT 001 in patients with $C$. difficile-associated diarrhoea (CDAD) in southern Germany [11]. Isolates corresponding to RT 001 did not contain the binary toxin genes $c d t A$ and $c d t B$ and displayed resistance to moxifloxacin and erythromycin [11].

In December 2007, a requirement for mandatory notification of severe CDI was introduced in Germany [12]. According to this requirement, severe $C D I$ was defined as pseudomembranous colitis confirmed by endoscopy or histology, or CDAD or toxic megacolon with positive laboratory results for $C$. difficile associated with one of the following conditions:

- readmission to the hospital because of recurrent CDI,

- admission to intensive care unit because of CDAD or its complications,

- abdominal surgery because of toxic megacolon, perforation or refractory colitis,

- death within 30 day after CDAD, with CDI as underlying cause or contributing to death,

- detection of RT 027.

The Hesse State Health Office (HSHO) receives notifications on severe CDI from local health authorities of the state of Hesse, which is located in western Germany and has approximately six million inhabitants. Following the introduction of the federal notification requirement, we initiated a pilot study to characterise $C$. difficile isolates associated with severe CDI in Hesse by offering for free a complete microbiological diagnostic service including culture, toxin detection, antimicrobial resistance testing and ribotyping to those healthcare facilities in Hesse that do not have access to these analyses. In this report, we present the results of our study during the first 16 months after introduction of these measures.

\section{Patients and methods}

\section{Study population}

From January 2008 to April 2009, 60 patients with notifiable CDI were reported by local health authorities via electronic notification system (SurvNet) to the HSHO. A total of 24 C. difficile isolates from 24 of these patients had been submitted by the microbiological laboratories of the respective hospitals to a 
national reference laboratory for $C$. difficile (Institute for Medical Microbiology, University of Mainz, or Robert Koch Institute (RKI), Wernigerode, Germany) for ribotyping. The ribotyping results of these isolates were reported to $\mathrm{HSHO}$ along with the case reports and corresponded in 23 of 24 cases to RT 027.

In addition, we received 22 stool samples from 17 patients with severe $\mathrm{CDI}$ that were sent to the microbiological laboratory of $\mathrm{HSHO}$ for detection and molecular typing of $\mathrm{C}$. difficile during the study period. Comparison of the electronic notification reports with the data of these 17 patients revealed that 12 of them had not been reported by the electronic notification system. These cases were additionally enrolled in this study. The 17 patients were hospitalised in 13 different hospitals. Seventeen isolates (one isolate per patient) were forwarded to the national reference laboratory at the RKI for PCR ribotyping.

\section{C. difficile culture, toxin analysis, and antimicrobial susceptibility testing}

Faecal culture for $C$. difficile was performed on C. difficileselective agar containing cycloserine, cefoxitin, and amphotericin $\mathrm{B}$ (Bio Mérieux) under anaerobic conditions. Identification of C. difficile was performed by routine microbiologic techniques and a rapid confirmatory latex agglutination test for $C$. difficile (Microgen Bioproducts). Twelve of $17 \mathrm{C}$. difficile isolates that were isolated in the $\mathrm{HSHO}$ laboratories were tested for in vitro toxin production with an ELISA detecting toxin A and/or B (Biopharm). Of the remaining five cases, four had been tested positive for toxin $A / B$ directly from the stool specimen and were therefore considered to be toxinpositive. One isolate was lost because of fungal contamination and could not be used for ELISA or antimicrobial susceptibility testing. Sixteen isolates were subjected to susceptibility testing for erythromycin and moxifloxacin by E-test (AB-Biodisc).

\section{PCR ribotyping}

PCR ribotyping was performed at the RKI according the protocol of Bidet et al. [13], except that PCR Products were run on $1.5 \%$ agarose gels in $1 \times$ TBE at 85 volts for $4 \mathrm{~h}$. Through cooperation with the reference laboratory for $C$. difficile at the Leiden University Medical Centre in the Netherlands and the German reference laboratory for gastrointestinal infections in Freiburg, the RKI accumulated a reference strain collection of 76 different C. difficile ribotypes, including 25 reference strains from the Cardiff Anaerobe Reference Laboratory in Wales, United Kingdom [14]. PCR ribotypes that differed from reference patterns by at least one band were assigned novel PCR ribotypes and marked with the prefix RKI [15]. Ribotyping at the University of Mainz was performed as described by Brazier et al. [6] by using the 25 reference strains from the Cardiff Anaerobe Reference Laboratory.

\section{Results}

\section{Study population}

From January 2008 to April 2009, a total of 72 severe CDI cases were reported to the HSHO by local health authorities or by clinicians in Hesse (Figure 1).

Thirty-eight patients (53\%) were male and 34 (47\%) were female. The patients' age ranged from 30 to 94 years with a median age of 80 years (Figure 2).

The clinical symptoms included diarrhoea (72 cases), recurrent infection leading to hospital admission (19 cases), pseudomembranous colitis (nine cases), sepsis (five cases), colitis (two cases), and colon perforation, peritonitis and pancreatitis (one case each). Twenty-three of the cases were reported because

\section{F I G U R E 1}

Cases of severe $C$. difficile infection reported from January 2008 to April 2009 in Hesse, Germany $(n=72)$

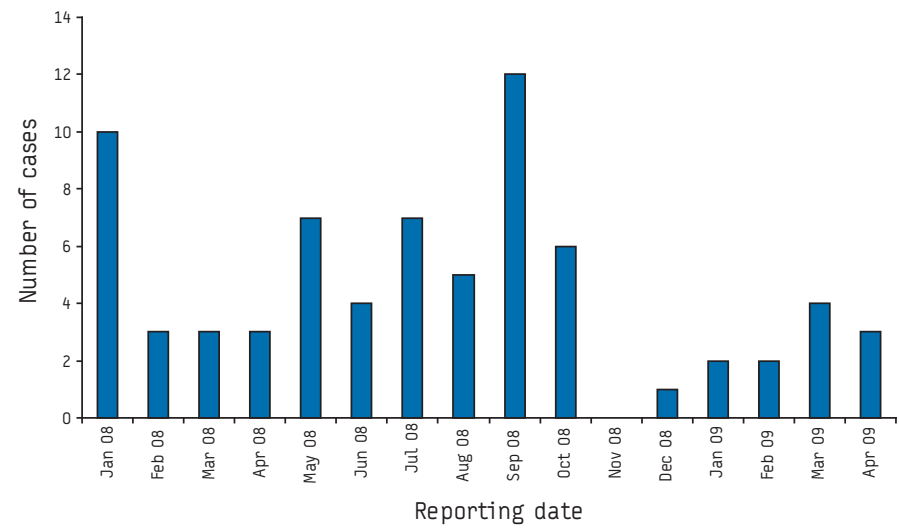

F I G U R E 2

Age distribution of patients with severe $C$. difficile infection in Hesse, Germany $(n=72)$

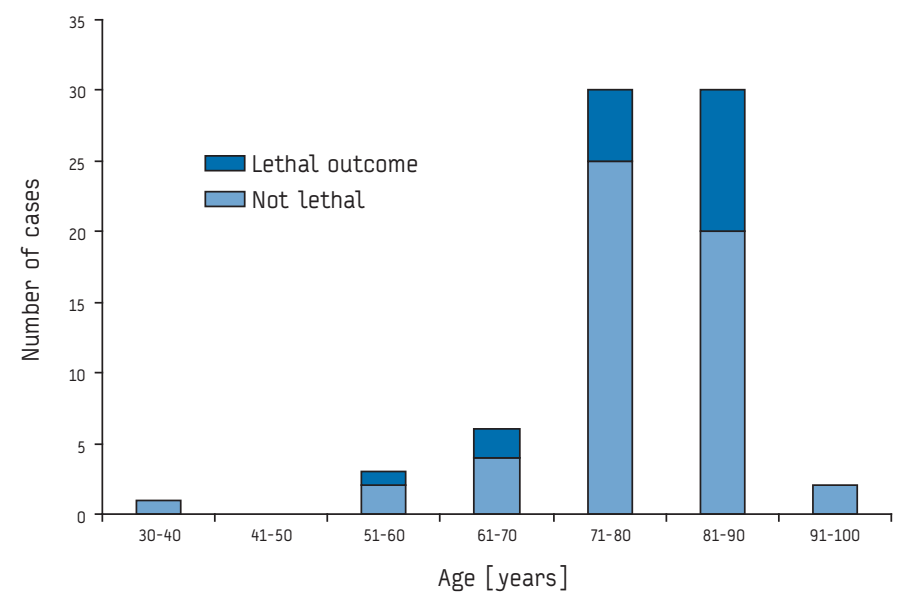

F I G U R E 3

Assignment of $C$. difficile isolates collected from patients with severe CDI to PCR ribotypes, Hesse, Germany $(n=41)$

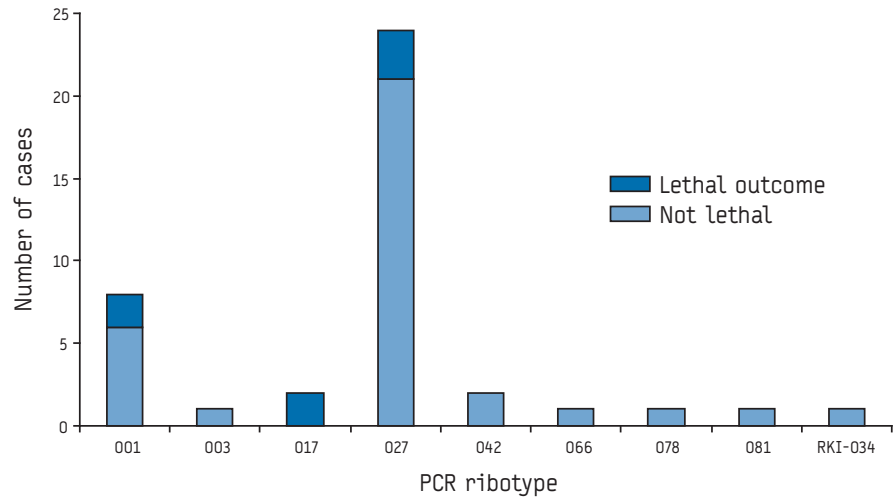


of detection of RT 027. The clinical outcome was disclosed in 60 cases (86\%). The infection was lethal within 30 days after diagnosis in 18 cases (25\%). Infection by $C$. difficile was reported as underlying cause of or contributing to death in 13 cases, and in one case as the most probable cause of death. The patients with lethal outcome that could be attributed to CDI were between 59 and 89 years-old, with a median age of 78 years.

\section{PCR ribotypes, toxin production, antimicrobial susceptibility}

Ribotyping results were available for 41 isolates obtained from 41 of the 72 patients with severe CDI. Twenty-four ribotyping results were reported to our institution via electronic notification system, while 17 isolates were isolated in the microbiological laboratory of our institution and forwarded for ribotyping to the national reference laboratory at the RKI. A total of 24 isolates were identified as RT 027, eight isolates as RT 001, two isolates each as RT 017 and 042, and one isolate each as RT 003, 066, 078 and 081. One isolate could not be assigned to any known RT and was designated as RKI-034 (Figure 3).

Production of toxin A and/or B was assessed in culture supernatants of the $12 \mathrm{C}$. difficile isolates cultured in our institution from patients with severe CDI. All isolates were tested positive for toxin $A$ and/or B production. Interestingly, direct toxin detection in stool samples was negative in four of these 12 cases, confirming the higher sensitivity of culture compared to direct toxin detection in stool samples. Antimicrobial susceptibility results were available for 16 isolates. Six of the eight RT 001 isolates were tested and displayed resistance to moxifloxacin and erythromycin. Both RT 017 isolates, one of the two RT 042 isolates and the RT 078 isolate were resistant to moxifloxacin. Six isolates were susceptible to moxifloxacin. These results suggest that resistance to moxifloxacin is not a specific marker for RT 027.

\section{Characterisation of $\boldsymbol{C}$. difficile isolates associated with lethal \\ infection}

Eighteen (25\%) patients had died during the hospitalisation period associated with severe CDI. Ribotyping results were available for seven of the cases with lethal outcome and identified RT 027 in three cases and RT 001 and 017 in two cases each (Figure 3). The clinical symptoms, previous antimicrobial therapy, and antimicrobial susceptibility results of these seven cases are summarised in the Table 1.

\section{Discussion}

In this study, we present the first results on surveillance of severe $\mathrm{CDI}$ in the state of Hesse with approximately six million inhabitants. A total of 72 cases of severe CDI were included in this study. Sixty cases were reported through the federal notification system, whereas 12 additional cases were enrolled because of our offer to analyse samples from patients with severe CDI in our diagnostic laboratory at no charge. Taking into account possible underreporting and the restricted use of microbiological diagnostic tools such as culture and ribotyping because of economic considerations, it can be hypothesised that the real incidence of severe CDI might be markedly higher in our region.

Sixty-nine (96\%) of 72 patients included in this study were older than 60 years. The median age was 80 years. We observed a high rate $(19 \%)$ of disease-related fatality in our study. Eleven of 14 patients with lethal outcome that was attributable to CDAD were older than 70 years. This finding is in accordance with the results of a recent study that identified advanced age (over 70 years) as a significant risk factor for illness and death among patients with CDAD [16]. However, it can not be ruled out that the emergence and circulation of epidemic and highly virulent $C$. difficile strain(s) may have contributed to an increased case fatality rate in our study.

Nine different $C$. difficile ribotypes were associated with severe $\mathrm{CDI}$ in our study. Ribotypes 027 and 001 were the most prevalent strains, while all other ribotypes were encountered only once or twice. Twenty-four of 41 typed isolates (59\%) were RT 027. Since detection of RT 027 represents a case definition criterion for severe $\mathrm{CDI}$ in Germany, the high proportion of RT 027 may at least partially be attributed to a sampling bias. However, since the majority of RT 027 isolates were reported from a distinct district, a local outbreak in a particular hospital in that region can not be excluded. Further studies are required to evaluate this hypothesis. Taken together, our data show unequivocally that $C$. difficile 027 has emerged and is prevalent in Hesse.

Eight isolates (20\%) were identified as RT 001 in this study. The high prevalence of RT 001 in our study is in accordance with

T A B L E

Clinical data of patients with lethal C. difficile infection for whom isolates were available for analysis and ribotyping $(\mathrm{n}=7)$

\begin{tabular}{|c|c|c|c|c|c|c|c|}
\hline $\begin{array}{l}\text { Patient, age, } \\
\text { sex }\end{array}$ & $\begin{array}{l}\text { Date of } \\
\text { reporting }\end{array}$ & $\begin{array}{l}\text { Hospital } \\
\text { department }\end{array}$ & Clinical symptoms & $\begin{array}{l}\text { Previous antimicrobial } \\
\text { therapy }\end{array}$ & $\begin{array}{l}\text { Erythro- } \\
\text { mycin }\end{array}$ & $\begin{array}{l}\text { Moxi- } \\
\text { floxacin }\end{array}$ & $\begin{array}{l}\text { PCR } \\
\text { ribotype }\end{array}$ \\
\hline Patient $1,83, \mathrm{f}$ & 9 Mar 2008 & medicine & CDAD, dialysis, hemi-colectomy, & $\begin{array}{l}\text { ceftriaxon, clarithromycin, } \\
\text { imipenem }\end{array}$ & n.d. & n.d. & 027 \\
\hline Patient 2, 62, f & 20 Mar 2008 & medicine & CDAD, colitis, peritonitis & $\begin{array}{l}\text { ceftriaxon, vancomycin, } \\
\text { metronidazole }\end{array}$ & $\mathrm{S}$ & $\mathrm{R}$ & 017 \\
\hline Patient $3,86, \mathrm{~m}$ & 22 Jul 2008 & medicine & $\begin{array}{l}\text { fracture, intracranial bleeding, } \\
\text { dialysis, CDAD }\end{array}$ & ceftriaxon & n.d. & n.d. & 027 \\
\hline Patient $4,83, \mathrm{~m}$ & 31 Jul 2008 & medicine & $\begin{array}{l}\text { urinary tract infection, CDAD, } \\
\text { colitis }\end{array}$ & ampicillin-sulbactam & $\mathrm{R}$ & $\mathrm{R}$ & 001 \\
\hline Patient $5,73, \mathrm{f}$ & 9 Sept 2008 & geriatrics & cystitis, CDAD, readmission & levofloxacin, vancomycin & n.d. & $\mathrm{R}$ & 027 \\
\hline Patient $6,72, \mathrm{~m}$ & 10 oct 2008 & urology & gastroenteritis, CDAD & unknown, metronidazole & $\mathrm{R}$ & $\mathrm{R}$ & 017 \\
\hline Patient $7,59, \mathrm{~m}$ & 11 Dec 2008 & medicine & pseudomembranous colitis, sepsis & $\begin{array}{l}\text { clarithromycin, amoxicillin, } \\
\text { ampicillin-sulbactam }\end{array}$ & $R$ & $\mathrm{R}$ & 001 \\
\hline
\end{tabular}

CDAD: Clostridium difficile-associated diarrhoea; n.d.: not defined; R: resistant; S: sensitive. 
the results of Borgmann et al. who found a high prevalence (55\%) of RT 001 in patients with CDAD in southern Germany in 2008 [11]. Thus, RT 001 appears to be a common $C$. difficile genotype in western and southern Germany. It is noteworthy that RT 001 used to be the most prevalent strain associated with hospital outbreaks in English hospitals in 2005, but its prevalence has declined to $7.8 \%$ of isolates in 2007-2008 [6]. Future studies are necessary to follow up the distribution of this ribotype in Germany.

One of the isolates in our study was identified as RT 078. An increased prevalence of $\mathrm{CDI}$ due to this ribotype in the Netherlands has been reported by Goorhuis et al. [17]. In the latter study, CDI due to both RT 078 and RT 027 presented with similar severity, but CDI associated with RT 078 affected a younger population and was more frequently community-associated. In our study, the patient suffering from severe CDI due to RT 078 was 60 years-old and therefore younger than the average. Our results indicate that RT 078 is prevalent in hospitals in Hesse. They are in agreement with the data by Rupnik et al. [18] who found RT 078 in $7.5 \%$ of $C$. difficile isolates collected from hospitals in Göttingen and the surrounding regions in the Lower Saxonia, Germany in 2006.

Ribotyping results were available for seven isolates associated with lethal CDI; three isolates were identified as RT 027, and two isolates each as RT 001 and 017. Our data suggest that, along with the hypervirulent RT 027, other toxigenic C. difficile strains such as RT 001 and 017 are associated with severe and lethal $\mathrm{CDI}$ in Hesse. It is noteworthy that ribotyping results were not available for half of the lethal cases of CDI in this study. Therefore, it is possible that also other ribotypes may be involved in severe CDI with lethal outcome. Our experience shows that offering the possibility to submit samples from patients with severe CDI to a specialised laboratory at no charge may help to collect more complete information.

In conclusion, the results presented here suggest that severe CDI is prevalent among hospitalised patients in Hesse. Severe CDI was associated with a high case fatality rate, especially in patients over 70 years of age. Nine different $C$. difficile ribotypes were associated with severe CDI. Lethal infections were observed in association with RT 001, 017, and 027. This study underlines the need for further studies on molecular epidemiology of $C$. difficile.

\section{Acknowledgements}

We thank the staff of local health authorities in Hesse for excellent cooperation. This project was supported by a grant of the Antibiotic Resistance Surveillance (ARS) programme of the German Federal Ministry of Health to WW.

\section{References}

1. Bartlett JG. Narrative review: the new epidemic of Clostridium difficileassociated enteric disease. Ann Intern Med. 2006;145(10):758-64.

2. Pépin J, Valiquette L, Alary ME, Villemure P, Pelletier A, Forget K, et al. Clostridium difficile-associated diarrhea in a region of Quebec from 1991 to 2003: a changing pattern of disease severity. CMAJ. 2004;171(5):466-72.

3. McDonald LC, Killgore GE, Thompson A, Owens RC Jr, Kazakova SV, Sambol SP, et al. An epidemic, toxin gene-variant strain of Clostridium difficile. $N$ Engl J Med. 2005;353(23):2433-41.

4. Loo VG, Poirier L, Miller MA, Oughton M, Libman MD, Michaud S, et al. A predominantly clonal multi-institutional outbreak of Clostridium difficileassociated diarrhea with high morbidity and mortality. N Engl J Med. 2005;353(23):2442-9.
5. Indra A, Huhulescu S, Fiedler A, Kernbichler S, Blaschitz M, Allerberger F Outbreak of Clostridium difficile 027 infection in Vienna, Austria 20082009. Euro Surveill. 2009;14(17):pii=19186. Available from: http://www. eurosurveillance.org/ViewArticle.aspx?ArticleId=19186

6. Brazier JS, Raybould R, Patel B, Duckworth G, Pearson A, Charlett A, et al. Distribution and antimicrobial susceptibility patterns of Clostridium difficile PCR ribotypes in English hospitals, 2007-08. Euro Surveill. 2008;13(41):pii=19000. Available from: http://www.eurosurveillance.org/ ViewArticle.aspx?ArticleId $=19000$

7. Kuijper EJ, Coignard B, Brazier JS, Suetens C, Drudy D, Wiuff C, et al. Update of Clostridium difficile-associated disease due to PCR ribotype 027 in Europe. Euro Surveill. 2007;12(6):pij=714. Available from: http://www.eurosurveillance. org/ViewArticle.aspx?ArticleId=714

8. Indra A, Huhulescu S, Hasenberger P, Schmid D, Alfery C, Würzner R, et al. First isolation of Clostridium difficile PCR ribotype 027 in Austria. Euro Surveill 2006;11(37):pii=3046. Available from: http://www.eurosurveillance. org/ViewArticle.aspx?ArticleId=3046

9. Kleinkauf N, Weiss B, Jansen A, Eckmanns T, Bornhofen B, Kühnen E, et al. Confirmed cases and report of clusters of severe infections due to Clostridium difficile PCR ribotype 027 in Germany. Euro Surveill. 2007;12(46):pii=3307. Available from: http://www.eurosurveillance.org/ ViewArticle.aspx?ArticleId $=3307$

10. Robert Koch Institute (RKI). [Clostridium difficile: On the state of reporting infections with a severe course in Germany]. Epidemiologisches Bulletin. 2008;15:117-9. German.

11. Borgmann S, Kist M, Jakobiak T, Reil M, Scholz E, von Eichel-Streiber C, et al. Increased number of Clostridium difficile infections and prevalence of Clostridium difficile PCR ribotype 001 in southern Germany. Euro Surveill. 2008;13(49):pii=19057. Available from: http://www.eurosurveillance.org/ ViewArticle.aspx?ArticleId $=19057$

12. Robert Koch Institute (RKI). [Clostridium difficile infections with a severe course: on mandatory reporting]. Epidemiologisches Bulletin. 2008;46:424. German.

13. Bidet P, Barbut F, Lalande V, Burghoffer B, Petit JC. Development of a new PCR-ribotyping method for Clostridium difficile based on ribosomal RNA gene sequencing. FEMS Microbiol Lett. 1999;175(2):261-6.

14. Stubbs SL, Brazier JS, O'Neill GL, Duerden BI. PCR targeted to the 16S-23S rRNA gene intergenic spacer region of Clostridium difficile and construction of a library consisting of 116 different PCR ribotypes. J Clin Microbiol. 1999;37(2):461-3.

15. Zaiss NH, Rupnik M, Kuijper EJ, Harmanus C, Michielsen D, Janssens K, et al. Typing Clostridium difficile strains based on tandem repeat sequences. BMC Microbiol. 2009;9:6.

16. Henrich TJ, Krakower D, Bitton A, Yokoe DS. Clinical risk factors for severe Clostridium difficile-associated disease. Emerg Infect Dis. 2009;15(3):415-22.

17. Goorhuis A, Bakker D, Corver J, Debast SB, Harmanus C, Notermans DW, et al. Emergence of Clostridium difficile infection due to a new hypervirulent strain, polymerase chain reaction ribotype 078. Clin Infect Dis. 2008;47(9):116270.

18. Rupnik M, Widmer A, Zimmermann O, Eckert C, Barbut F. Clostridium difficile toxinotype V, ribotype 078, in animals and humans. J Clin Microbiol. 2008;46(6):2146. 